\section{SOLIDIFICATION OF METALS.}

THE first Report to the Beilby Prize Committee of the Institute of Metals on "The Solidification of Metals from the Liquid State," by Dr. C. H. Desch, is published in the current number of the Journal of the Institute. It consists of a very interesting and comprehensive review of the literature bearing on the subject, in conformity with the first part of the scheme of Dr. Beilby, which included both the preparation of a summary of the existing knowledge on the subject of the solidification of metals and an experimental investigation of certain parts of the subject. The report deals first with the cellular structure of metals, and it is shown that more than one apparently cellular structure may be detected in metals under suitable conditions. The crystallisation of metals is next approached, and the formation of crystallites or crystal skeletons. Attention is very rightly directed to the few opportunities which occur for the goniometrical and physical study of isolated crystals of metals. For there can be no doubt that much valuable information would be obtained from such an investigation, which would also be of particular value as throwing light on the phenomenon of hardness. In a solidifying metal crystallites start at numerous independent centres, and each grows as a crystal until interfered with by its neighbours, which interference gives rise to the so-called "allotriomorphic" formations of irregularly bounded crystals.

The foam-structure theory of Quinclee is next dealt with, and shown to be carried much too far in its application to metals; for the theory affords no explanation of the absolutely firmly established geometrical properties of crystals. Cellular structures in cooling liquids are next described, and then comes a most interesting section on liquid crystals, in which it is pleasant to see that Dr. Desch gives full credit to the marvellously detailed work of Lehmann, who has now established it beyond doubt that there are substances, usually organic, which unite the properties of a crystal and a liquid, and that a definite arrangement of the molecules may persist in the liquid state.

The influence of surface tension is then discussed, and the existence of a metastable limit in the case of undercooling, together with the phenomenon of change of volume on solidification. Finally, the possibility of a thrust being exerted by growing crystals is debated from the evidence available, and the fact pointed out that there is yet no clear evidence of any effect which cannot be attributed to change of volume during change of state. The net result of the report is to indicate the immense field open for investigation, and one which has bearings, not only on pure science, but on industrial problems of the greatest importance and magnitude.

\section{THE AUSTRALIAN MEETING OF THE BRITISH ASSOCIATION.}

inacgural Address by Prof. Willian Bateson, M.A., F.R.S., PresideNt.

PART II.-SYDNEY.

AT Melbourne I spoke of the new knowledge of the properties of living things which Mendelian analysis has brought us. I indicated how these discoveries are affecting our outlook on that old problem of natural history, the origin and nature of species, and the chief conclusion I drew was the negative one, that, though we must hold to our faith in the evolution of species, there is little evidence as to how it has come about, and no clear proof that the process is continuing in any considerable degree at the present time. The thought uppermost in our minds is that knowledge of the nature of life is altogether too slender to warrant speculation on these fundamental subjects. Did we presume to offer such speculations they would have no more value than those which alchemists might have made as to the nature of the elements. But though in regard to these theoretical aspects we must confess to such deep ignorance, enough has been learnt of the general course of heredity within a single species to justify many practical conclusions which cannot in the main be shaken. I propose now to develop some of these conclusions in regard to our own species, Man.

In my former Address I mentioned the condition of certain animals and plants which are what we call "polymorphic." Their populations consist of individuals of many types, though they breed freely together with perfect fertility. In cases of this kind which have been sufficiently investigated it has been found that these distinctions-sometimes very great and affecting most diverse features of organisationare due to the presence or absence of elements, or factors as we call them, which are treated in heredity as separate entities. These factors and their combinations produce the characteristics which we perceive. No individual can acquire a particular characteristic unless the requisite factors entered into the composition of that individual at fertilisation, being received either from the father or from the mother or from both, and consequently no individual can pass on to his offspring positive characters which he does not himself possess. Rules of this kind have already been traced in operation in the human species; and though I admit that an assumption of some magnitude is involved when we extend the application of the same system to human characteristics in general, yet the assumption is one which I believe we are fully justified in making. With little hesitation we can now declare that the potentialities and aptitudes. physical as well as mental, sex, colours, powers of work or invention, Tiability to diseases, possible duration of life, and the other features by which the nembers of a mixed population differ from each other, are determined from the moment of fertilisation; and by all that we know of heredity in the forms of life with which we can experiment we are compelled to believe that these qualities are in the main distributed on a factorial system. By changes in the outward conditions of life the expression of some of these powers and features may be excited or restrained. For the development of some an external opportunity is needed, and if that be withheld the character is never seen, any more than if the body be starved can the full height be attained; but such influences are superficial and do not alter the genetic constitution.

The factors which the individual receives from his parents and no others are those which he can transmit to his offspring; and if a factor was received from one parent only, not more than half the offspring, on an average, will inherit it. What is it that has so long prevented mankind from discovering such simple facts? Primarily the circumstance that as man must have two parents it is not possible quite easily to detect the contributions of each. The individual body is a double structure, whereas the germcells are single. Two germ-cells unite to produce each individual body, and the ingredients they respectively contribute interact in ways that leave the ultimate product a medley in which it is difficult to identify the several ingredients. When, however, their effects are conspicuous the task is by no means impossible. In part also even phrsiologists have been blinded by the survival of ancient and obscurantist 
conceptions of the nature of man by which they were discouraged from the application of any rigorous analysis. Medical literature still abounds with traces of these archaisms, and, indeed, it is only quite recently that prominent horse-breeders have come to see that the dam matters as much as the sire. For them, though vast pecuniary considerations were involved, the old "homunculus" theory was good enough. We were amazed at the notions of genetic physiology which Prof. Baldwin Spencer encountered in his wonderful researches among the natives of Central Australia; but in truth, if we reflect that these problems have engaged the attention of civilised man for ages, the fact that he, with all his powers of recording and deduction, failed to discover any part of the Mendelian system is almost as amazing. The popular notion that any parents can have any kind of children within the racial limits is contrary to all experience, yet we have gravely entertained such ideas. As I have said elsewhere, the truth might have been found out at any period in the world's history if only pedigrees had been drawn the right way up. If, instead of exhibiting the successive pairs of progenitors who have contributed to the making of an ultimate individual, some one had had the idea of setting out the posterity of a single ancestor who possessed a marked feature such as the Habsburg lip, and showing the transmission of this feature along some of the descending branches and the permanent loss of the feature in collaterals, the essential truth that heredity can be expressed in terms of presence and absence must have at once become apparent. For the descendant is not, as he appears in the conventional pedigree, a sort of pool into which each tributary ancestral stream has poured something, but rather a conglomerate of ingredient-characters taken from his progenitors in such a way that some ingredients are represented and others are omitted.

Let me not, however, give the impression that the unravelling of such descents is easy. Even with fairly full details, which in the case of man are very rarely to be had, many complications occur, often preventing us from obtaining more than a rough general indication of the system of descent. The nature of these complications we partly understand from our experience of animals and plants which are amenable to breeding under careful restrictions, and we know that they are mostly referable to various effects of interaction between factors by which the presence of some is masked.

Necessarily the clearest evidence of regularity in the inheritance of human characteristics has been obtained in regard to the descent of marked abnormalities of structure and congenital diseases. Of the descent of ordinary distinctions such as are met with in the normal healthy population we know little for certain. Hurst's evidence, that two parents both with light-coloured eyes-in the strict sense, meaning that no pigment is present on the front of the iris-do not have dark-eyed children, still stands almost alone in this respect. With regard to the inheritance of other colour-characteristics some advance has been made, but everything points to the inference that the genetics of colour and many other features in man will prove exceptionally complex. There are, however, plenty of indications of system comparable with those which we trace in various animals and plants, and we are assured that to extend and clarify such evidence is only a matter of careful analysis. For the present, in asserting almost any general rules for human descent, we do right to make large reservations for possible exceptions. It is tantalising to have to wait, but of the ultimate result there can be no doubt.

NO. 2339, VOL. 93]
I spoke of complications. Two of these are worth illustrating here, for probably both of them play a great part in human genetics. It was discovered by Nilsson-Ehle, in the course of experiments with certain wheats, that several factors having the same power may co-exist in the same individual. These cumulative factors do not necessarily produce a cumulative effect, for any one of them may suffice to give the full result. Just as the pure-bred tall pea with its two factors for tallness is no taller than the cross-bred with a single factor, so these wheats with three pairs of factors for red colour are no redder than the ordinary reds of the same family. Similar observations have been made by East and others. In some cases, as in the Primulas studied by Gregory, the effect is cumulative. These results have been used with plausibility by Davenport and the American workers to elucidate the curious case of the mulatto. If the descent of colour in the cross between the negro and the white man followed the simplest rule, the ofispring of two first-cross mulattos would be, on an average, one black: two mulattos: one white, but this is notoriously not so. Evidence of some segregation is fairly clear, and the deficiency of real whites may perhaps be accounted for on the hypothesis of cumulative factors, though by the nature of the case strict proof is not to be had. But at present I own to a preference for regarding such examples as instances of imperfect segregation. The series of germcells produced by the cross-bred consists of some with no black, some with full black, and others with intermediate quantities of black. No statistical tests of the condition of the gametes in such cases exist, and it is likely that by choosing suitable crosses all sorts of conditions may be found, ranging from the simplest case of total segregation, in which there are only two forms of gametes, up to those in which there are all intermediates in various proportions. This at least is what general experience of hybrid products leads me to anticipate. Segregation is somehow effected by the rhythms of cell-division, if such an expression may be permitted. In some cases the whole factor is so easily separated that it is swept out at once; in others it is so intermixed that gametes of all degrees of purity may result. That is admittedly a crude metaphor, but as yet we cannot substitute a better. $\mathrm{Be}$ all this as it may, there are many signs that in human heredity phenomena of this kind are common, whether they indicate a multiplicity of cumulative factors or imperfections in segregation. Such phenomena, however, in no way detract from the essential truths that segregation occurs, and that the organism cannot pass on a factor which it has not itself received.

In human heredity we have found some examples, and I believe that we shall find many more, in which the descent of factors is limited by sex. The classical instances are those of colour-blindness and hæmophilia. Both these conditions occur with much greater frequency in males than in females. Of colour-blindness at least we know that the sons of the colour-blind man do not inherit it (unless the mother is a transmitter) and do not transmit it to their children of either sex. Some, probably all, of the daughters of the colour-blind father inherit the character, and though not themselves colour-blind, they transmit it to some (probably, on an average, half) of their offspring of both sexes. For since these normal-sighted women have only received the colourblindness from one side of their parentage, only half their offspring, on an average, can inherit it. The sons who inherit the colour-blindness will be colourblind, and the inheriting daughters become themselves again transmitters. Males with normal colour-vision, 
whatever their own parentage, do not have colourblind descendants, unless they marry transmitting women. There are points still doubtful in the interpretation, but the critical fact is clear, that the germcells of the colour-blind man are of two kinds: (i) those which do not carry on the affection and are destined to take part in the formation of sons; and (ii) those which do carry on the colour-blindness and are destined to form daughters. There is evidence that the ova also are similarly predestined to form one or other of the sexes, but to discuss the whole question of sex-determination is beyond my present scope. The descent of these sex-limited affections nevertheless calls for mention here, because it is an admirable illustration of factorial predestination. It moreover exemplifies that parental polarity of the zygote to which $I$ alluded in my first Address, a phenomenon which we suspect to be at the bottom of various anomalies of heredity, and suggests that there may be truth in the popular notion that in some respects sons resemble their mothers and daughters their fathers.

As to the descent of hereditary diseases and malformations, however, we have abundant data for deciding that many are transmitted as dominants and a few as recessives. The most remarkable coliection of these data is to be found in family histories of diseases of the eye. Neurology and dermatology have also contributed many very instructive pedigrees. In great measure the ophthalmological material was collected by Edward Nettleship, for whose death we so lately grieved. After retiring from practice as an oculist he devoted several years to this most laborious task. He was not content with hearsay evidence, but travelled incessantly, personally examining all accessible members of the families concerned, working in such a way that his pedigrees are models of orderly observation and recording. His zeal stimulated many younger men to take part in the work, and it will now go on, with the result that the systems of descent of all the common hereditary diseases of the eye will soon be known with approximate accuracy.

Give a little imagination to considering the chief deduction from this work. Technical details apart, and granting that we cannot wholly interpret the numerical results, sometimes noticeably more and sometimes fewer descendants of these patients being affected than Mendelian formulæ would indicate, the expectation is that in the case of many diseases of the eye a large proportion of the children, grandchildren, and remoter descendants of the patients will be affected with the disease. Sometimes it is only defective sight that is transmitted; in other cases it is blindness, eiher from birth or coming on at some later age. The most striking example perhaps is that of a form of night-blindness still prevalent in a district near Montpellier, which has affected at least I3o persons, all descending from a single affected individual ${ }^{1}$ who came into the country in the seventeenth century. The transmission is in every case through an affected parent, and no normal has been known to pass on the condition. Such an example well serves to illustrate the fixity of the rules of descent. Similar instances might be recited relating to a great variety of other conditions, some trivial, others grave.

At various times it has been declared that men are born equal, and that the inequality is brought about by unequal opportunities. Acquaintance with the pedigrees of disease soon shows the fatuity of such

1 The first human descent proved to follow Mendelian rules was that of a serious malformation of the hand studied by Farabee in America. Drink water subsequently worked out pedigrees for the same malformation in England. After many attempts, he now tells me that he has succeeded in proving that the American family and one of his own had an abnormal ancestor in common, five generations ago. fancies. The same conclusion, we may be sure, would result from the true representation of the descent of any human faculty. Never since Galton's publications can the matter have been in any doubt. At the time he began to study family histories even the broad significance of heredity was frequently denied, and resemblances to parents or ancestors were looked on as interesting curiosities. Inveighing against hereditary political institutions, Tom Paine remarks that the idea is as absurd as that of an "hereditary wise man," or an "hereditary mathematician," and to this day I suppose many people are not aware that he is saying anything more than commonly foolish. We, on the contrary, would feel it something of a puzzle if two parents, both mathematically gifted, had any children not mathematicians. Gaiton first demonstrated the overwhelming importance of these considerations, and had he not been misled, partly by the theory of pangenesis, but more by his mathematical instincts and training, which prompted him to apply statistical treatment rather than qualitative analysis, he might, not improbably, have discovered the essential facts of Mendelism.

It happens rarely that science has anything to offer to the common stock of ideas at once so comprehensive and so simple that the courses of our thoughts are changed. Contributions to the material progress of mankind are comparatively frequent. They result at once in application. Transit is quickened; communication is made easier; the food-supply is increased and population multiplied. By direct application to the breeding of animals and plants such results must even flow from Mendel's work. But I imagine the greatest practical change likely to ensue from modern genetic discovery will be a quickening of interest in the true nature of man and in the biology of races. I have spoken cautiously as to the evidence for the operation of any simple. Mendelian system in the descent of human faculty; yet the certainty that systems which differ from the simpler schemes only in degree of complexity are at work in the distribution of characters among the human population cannot fail to influence our conceptions of life and of ethics, lead. ing perhaps ultimately to modification of social usage. That change cannot but be in the main one of simplification. The eighteenth century made great pretence of a return to nature, but it did not occur to those philosophers first to inquire what nature is; and perhaps not even the patristic writings contain fantasies much further from physiological truth than those which the rationalists of the "Encyclopædia" adopted as the basis of their social schemes. For men are so far from being born equal or similar that to the naturalist they stand as the very type of a polymorphic species. Even most of our local races consist of many distinct strains and individual types. From the population of any ordinary English town as many distinct human breeds could in a few generations be isolated as there are now breeds of dogs, and indeed such a population in its present state is much what the dogs of Europe would be in ten vears' time but for the interference of the fanciers. Even as at present constituted, owing to the isolating effects of instinct, fashion, occupation, and social class, many incipient strains already exist.

In one respect civilised man differs from all other species of animal or plant in that, having prodigious and ever-increasing power over nature, he invokes these powers for the preservation and maintenance of many of the inferior and all the defective members of his species. The inferior freely multiply, and the defective, if their defects be not so grave as to lead to their detention in prisons or asylums, multiply also without restraint. Heredity being strict in its action, 
the consequences are in civilised countries much what they would be in the kennels of the dog-breeder who continued to preserve all his puppies, good and bad: the proportion of defectives increases. The increase is so considerable that outside every great city there is a smaller town inhabited by defectives and those who wait on them. Round London we have a ring of such towns with some 30,000 inhabitants, of whom about 28 , ooo are defective, largely, though of course by no means entirely, bred from previous generations of defectives. Now, it is not for us to consider practical measures. As men of science we observe natural events and deduce conclusions from them. I may perhaps be allowed to say that the remedies proposed in America, in so far as they aim at the eugenic regulation of marriage on a comprehensive scale, strike me as devised without regard to the needs either of individuals or of a modern State. Undoubtedly if they decide to breed their population of one uniform puritan grey, they can do it in a few generations; but I doubt if timid respectability will make a nation happy, and I am sure that qualities of a different sort are needed if it is to compete with more vigorous and more varied communities. Everyone must have a preliminary sympathy with the aims of eugenists both abroad and at home. Their efforts at the least are doing something to discover and spread truth as to the physiological structure of society. The spirit of such organisations, however, almost of necessity suffers from a bias towards the accepted and the ordinary, and if they had power it would go hard with many ingredients of society that could be ill-spared. I notice an ominous passage in which even Galton, the founder of eugenics, feeling perhaps some twinge of his Quaker ancestry, remarks that "as the Bohemianism in the nature of our race is destined to perish, the sooner it goes, the happier for mankind." It is not the eugenists who will give us what Plato has called divine releases from the common ways. If some fancier with the catholicity of Shakespeare would take us in hand, well and good; but I would not trust even Shakespeares meeting as a committee. Let us remember that Beethoven's father was an habitual drunkard and that his mother died of consumption. From the genealogy of the patriarchs also we learn-what may very well be the truth-that the fathers of such as dwell in tents, and of all such as handle the harp or organ, and the instructor of every artificer in brass and iron-the founders, that is to say, of the arts and the sciencescame in direct descent from Cain, and not in the posterity of the irreproachable Seth, who is to us, as he probably was also in the narrow circle of his own contemporaries, what naturalists call a nomen nudum.

Genetic research will make it possible for a nation to elect by what sort of beings it will be represented not very many generations hence, much as a farmer can decide whether his byres shall be full of shorthorns or Herefords. It will be very surprising indeed if some nation does not make trial of this new power. They may make awful mistakes, but I think they will try.

Whether we like it or not, extraordinary and farreaching changes in public opinion are coming to pass. Man is just beginning to know himself for what he is -a rather long-lived animal, with great powers of enjoyment if he does not deliberately forgo them. Hitherto superstition and mythical ideas of sin have predominantly controlled these powers. Mysticism will not die out : for those strange fancies knowledge is no cure; but their forms may change, and mysticism as a force for the suppression of joy is happily losing its hoid on the modern world. As in the decay of earlier religions Ushabti dolls were substituted for human victims, so telepathy, necromancy, and other harmless toys take the place of eschatology and the inculcation of a ferocious moral code. Among the civilised races of Europe we are witnessing an emancipation from traditional control in thought, in art, and in conduct which is likely to have prolonged and wonderful influences. Returning to freer or, if you will, simpler conceptions of life and death, the coming generations are determined to get more out of this world than their forefathers did. Is it then to be supposed that when science puts into their hand means for the alleviation of suffering immeasurable, and for making this world a happier place, that they will demur to using those powers? The intenser struggle between communities is only now beginning, and with the approaching exhaustion of that capital of energy stored in the earth before man began it must soon becomes still more fierce. In England some of our great-grandchildren will see the end of the easily accessible coal, and, failing some miraculous discovery of available energy, a wholesale reduction in population. There are races who have shown themselves able at a word to throw off all tradition and take into their service every power that science has yet offered them. Can we expect that they, when they see how to rid themselves of the ever-increasing weight of a defective population, will hesitate? The time cannot be far distant when both individuals and communities will begin to think in terms of biological fact, and it behoves those who lead scientific thought carefully to consider whither action should lead. At present I ask you merely to observe the facts. The powers of science to preserve the defective are now enormous. Every year these powers increase. This course of action must reach a limit. To the deliberate intervention of civilisation for the preservation of inferior strains there must sooner or later come an end, and before long nations will realise the responsibility they have assumed in multiplying these "cankers of a calm world and a long peace."

The definitely feeble-minded we may with propriety restrain, as we are beginning to do even in England, and we may safely prevent unions in which both parties are defective, for the evidence shows that as a rule such marriages, though often prolific, commonly produce no normal children at all. The union of such social vermin we should no more permit than we would allow parasites to breed on our own bodies. Further than that in restraint of marriage we ought not to go, at least not yet. Something too may be done by a reform of medical ethics. Medical students are taught that it is their duty to prolong life at whatever cost in suffering. This may have been right when diagnosis was uncertain and interference usually of small effect; but deliberately to interfere now for the preservation of an infant so gravely diseased that it can never be happy or come to any good is very like wanton cruelty. In private few men defend such interference. Most who have seen these cases lingering on agree that the system is deplorable, but ask where can any line be drawn. The biologist would reply that in all ages such decisions have been made by civilised communities with fair success both in regard to crime and in the closely analogous case of lunacy. The real reason why these things are done is because the world collectively cherishes occult views of the nature of life, because the facts are realised by few, and because between the legal mind-to which society has become accustomed to defer-and the seeing eye, there is such physiological antithesis that scarcely can they be combined in the same body. So soon as scientific knowledge becomes common pro. perty, views more reasonable and, I may add, more humane, are likely to prevail.

To all these great biological problems that modern society must sooner or later face there are many NO. 2339, VOL. 93] 
aspects besides the obvious ones. Infant mortality we are asked to iament without the slightest thought of what the world would be like if the majority of these infants were to survive. The decline in the birth-rate in countries already over-populated is often deplored, and we are told that a nation in which population is not rapidly increasing must be in a decline. The slightest acquaintance with biology, or even school-boy natural history, shows that this inference may be entirely wrong, and that before such a question can be decided in one way or the other, hosts of considerations must be taken into account. In normal stable conditions population is stationary. The laity never appreciates, what is so clear to a biologist, that the last century and a quarter, corresponding with the great rise in population, has been an altogether exceptional period. To our species this period has been what its early years in Australia were to the rabbit. The exploitation of energy-capital of the earth in coal, development of the new countries, and the consequent pouring of food into Europe, the application of antiseptics, these are the things that have enabled the human population to increase. I do not doubt that if population were more evenly spread over the earth it might increase very much more; but the essential fact is that under any stable conditions a limit must be reached. A pair of wrens will bring off a dozen young every year, but each year you will find the same number of pairs in your garden. In England the limit beyond which under present conditions of distribution increase of population is a source of suffering rather than of happiness has been reached already. Younger communities living in territories largely vacant are very probably right in desiring and encouraging more population. Increase, may, for some temporary reason, be essential to their prosperity. But those who live, as I do, among thousands of creatures in a state of semistarvation will realise that too few is better than too many, and will acknowledge the wisdom of Ecclesiasticus who said "Desire not a multitude of unprofitable children."

But at least it is often urged that the decline in the birth-rate of the intelligent and successful sections of the population-I am speaking of the older communities-is to be regretted. Even this cannot be granted without qualification. As the biologist knows, differentiation is indispensable to progress. If population were homogeneous civilisation would stop. In every army the officers must be comparatively few. Consequently, if the upper strata of the community produce more children than will recruit their numbers some must fall into the lower strata and increase the pressure there. Statisticians tell us that an average of four children under present conditions is sufficient to keep the number constant, and as the expectation of life is steadily improving we may perhaps contemplate some diminution of that number without alarm.

In the study of history biological treatment is only beginning to be applied. For us the causes of the success and failure of races are physiological events, and the progress of man has depended upon a chain of these events, like those which have resulted in the "improvement" of the domesticated animals and plants. It is obvious. for example, that had the cereals never been domesticated cities could scarcely have existed. But we mav go further, and say that in temperate countries of the Old World (having neither rice nor maize) populations concentrated in large cities have been made possible by the appearance of a "thrashable" wheat. The ears of the wild wheats break easily to pieces, and the grain remains in the thick husk. Such wheat can be used for food, but not readily. Ages before written history began, in some unknown place, plants, or more likely a plant, of wheat lost the dominant factor to which this brittleness is due, and the recessive, thrashable wheat resulted. Some man noticed this wonderful novelty, and it has been disseminated over the earth. The original variation may well have occurred once only, in a single germ-cell.

So must it have been with Man. Translated into terms of factors, how has that progress in control of nature which we call civilisation been achieved? By the sporadic appearance of variations, mostly, perhaps all, consisting in a loss of elements, which inhibit the free working of the mind. The members of civilised communities, when they think about such things at all, imagine the process a gradual one, and that they themselves are active agents in it. Few, however, contribute anything but their labour; and except in so far as they have freedom to adopt and imitate, their physiological composition is that of an earlier order of beings. Annul the work of a few hundreds-I might almost say scores-of men, and on what plane of civilisation should we be? We should not have advanced beyond the medieval stage without printing, chemistry, steam, electricity, or surgery worthy the name. These things are the contributions of a few excessively rare minds. Galton reckoned those to whom the term "illustrious" might be applied as one in a million, but in that number he is, of course, reckoning men famous in ways which add nothing to universal progress. To improve by subordinate invention, to discover details missed, even to apply knowledge never before applied, all these things need genius in some degree, and are far beyond the powers of the average man of our race; but the true pioneer, the man whose penetration creates a new world, as did that of Newton and of Pasteur, is inconceivably rare. But for a few thousands of such men, we should perhaps be in the Palæolithic era, knowing neither metals, writing. arithmetic, weaving, nor pottery.

In the history of art the same is true, but with this remarkable difference, that not only are gifts of artistic creation very rare, but even the faculty of artistic enjoyment, not to speak of higher powers of appreciation, is not attained without variation from the common type. I am speaking, of course, of the non-Semitic races of modern Europe, among whom the power whether of making or enjoying works of art is confined to an insignificant number of individuals. Appreciation can in some degree be simulated, but in our population there is no widespread physiological appetite for such things. When detached from the centres where they are made by others most of us pass' our time in great contentment, making nothing that is beautiful, and quite unconscious of any deprivation. Musical taste is the most notable exception, for in certain races-for example, the Welsh and some of the Germans-it is almost universal. Otherwise artistic faculty is still sporadic in its occurrence. The case of music well illustrates the application of renetic analysis to human faculty. No one disputes that musicail ability is congenital. In its fuller manifestation it demands sense of rhythm, ear, and special nervous and muscular powers. Each of these is separable and doubtless genetically distinct. Each is the consequence of a special departure from the common type. Teaching and external influences are powerless to evoke these faculties, though their development may be assisted. The only conceivable way in which the people of England, for example, could become a musical nation would be by the gradual rise in the proportional 
numbers of a musical strain or strains until the present type became so rare as to be negligible. It by no means follows that in any other respect the resulting population would be distinguishable from the present one. Difficulties of this kind beset the efforts of anthropologists to trace racial origins. It must continually be remembered that most characters are independently transmitted and capable of such recombination. In the light of Mendelian knowledge the discussion whether a race is pure or mixed loses almost all significance. A race is pure if it breeds pure and not otherwise. Historically we may know that a race like our own was, as a matter of fact, of mixed origin. But a character may have been introduced by a single individual, though subsequently it becomes common to the race. This is merely a variant on the familiar paradox that in the course of time if registration is accurate we shall all have the same surname. In the case of music, for instance, the gift, originally perhaps from a Welsh source, might permeate the nation, and the question would then arise whether the nation, so changed, was the English nation or not.

Such a problem is raised in a striking form by the population of modern Greece, and especially of Athens. The racial characteristics of the Athenian of the fifth century B.c. are vividly described by Galton in "Hereditary Genius." The fact that in that period a population, numbering many thousands, should have existed, capable of following the great plays at a first hearing, revelling in subtleties of speech, and thrilling with passionate delight in beautiful things, is physiologically a most singular phenomenon. On the basis of the number of illustrious men produced by that age Galton estimated the average intelligence as at least two of his degrees above our own, differing from us as much as we do from the negro. A few generations later the display was over. The origin of that constellation of human genius which then blazed out is as yet beyond all biological analvsis, but I think we are not altogether without suspicion of the sequence of the biological events. If I visit a poultry-breeder who has a fine stock of thoroughbred game fowls breeding true, and ten years later--that is to say ten fowl-generations later-I go again and find scarcely a recognisable game-fowl on the place, I know exactly what has happened. One or two birds of some other or of no breed must have strayed in and their progeny been left undestroyed. Now in Athens we have many indications that up to the beginning of the fifth century so long as the phratries and gentes were maintained in their integrity there was rather close endogamy, a condition giving the best chance of producing a homogeneous population. There was no lack of material from which intelligence and artistic power might be derived. Sporadically these qualities existed throughout the ancient Greek world from the dawn of history, and, for example, the vase-painters, the makers of the Tanagra figurines, and the gem-cutters were presumably pursuing family crafts, much as are the actorfamilies $^{2}$ of England or the professorial families of Germany at the present day. How the intellectual strains should have acquired predominance we cannot tell, but in an in-breeding community homogeneity at least is not surprising. At the end of the sixth century came the "reforms" of Cleisthenes (507 B.c.), which sanctioned foreign marriages and admitted to citizenship a number not only of resident aliens but also of manumitted slaves. As Aristotle says, Cleisthenes legislated with the deliberate purpose of breaking up the phratries and gentes, in order that the

2 For tables of these families, see the Supplement to "Who's Who in the Theatre."

NO. 2339, VOL. 93] various sections of the population might be mixed up as much as possible, and the old tribal associations abolished. The "reform" was probably a recognition and extension of a process already begun; but is it too much to suppose that we have here the effective beginning of a series of genetic changes which in a few generations so greatly altered the character of the people? Under Pericles the old law was restored (45 ${ }^{\mathrm{r}}$ B.c.), but losses in the great wars led to further laxity in practice, and though at the end of the fifth century the strict rule was re-enacted that a citizen must be of citizen-birth on both sides, the population by that time may well have become largely mongrelised.

Let me not be construed as arguing that mixture of races is an evil: far from it. A population like our own, indeed, owes much of its strength to the extreme diversity of its components, for they contribute a corresponding abundance of aptitudes. Everything turns on the nature of the ingredients brought in, and I am concerned solely with the observation that these genetic disturbances lead ultimately to great and usually unforeseen changes in the nature of the population.

Some experiments of this kind are going on at the present time, in the United States, for example, on a very large scale. Our grand-children may live to see the characteristics of the American population entirely altered by the vast invasion of Italian and other South European elements. We may expect that the Eastern States, and especially New England, the people of which still exhibit the fine Puritan qualities with their appropriate limitations, absorbing little of the alien elements, will before long be in feelings and aptitudes very notably differentiated from the rest. In Japan, also, with the abolition of the feudal system and the rise of commercialism, a change in population has begun which may be worthy of the attention of naturalists in that country. Till the revolution the Samurai almost always married within their own class, with the result, as I am informed, that the caste had fairly recognisable features. The changes of I868 and the consequent impoverishment of the Samurai have brought about a beginning of disintegration which may not improbably have perceptible effects.

How many genetic vicissitudes has our own peerage undergone! Into the hard-fighting stock of medieval and Plantagenet times have successively been crossed the cunning shrewdness of Tudor statesmen and courtiers, the numerous contributions of Charles II. and his concubines, reinforcing peculiar and persistent attributes which popular imagination especially regards as the characteristic of peers, ultimately the heroes of finance and industrialism. Definitely intellectual elements have been sporadically added, with rare exceptions, however, from the ranks of lawyers and politicians. To this aristocracy art, learning, and science have contributed sparse ingredients, but these mostly chosen for celibacy or childlessness. A remarkable body of men, nevertheless; with an average "horse-power," as Samuel Butler would have said, far exceeding that of any random sample of the middle-class. If only man could be reproduced by budding what a simplification it would be! In vegetative reproduction heredity is usually complete. The Washington plum can be divided to produce as many identical individuals as are required. If, say, Washington, the statesman, or preferably King Solomon, could similarly have been propagated, all the nations of the earth could have been supplied with ideal rulers.

Historians commonly ascribe such changes as occurred in Athens, and will almost certainly come 
to pass in the United States, to conditions of life and especially to political institutions. These agencies, however, do little unless they are such as to change the breed. External changes may indeed give an opportunity to special strains, which then acquire ascendency. The industrial developments which began at the end of the eighteenth century, for instance, gave a chance to strains till then submerged, and their success involved the decay of most of the old aristocratic families. But the demagogue who would argue from the rise of the one and the fall of the other that the original relative positions were not justifiable altogether mistakes the facts.

Conditions give opportunities but cause no variations. For example, in Athens, to which $I$ just referred, the universality of cultivated discernment could never have come to pass but for the institution of slavery which provided the opportunity, but slavery was in no sense a cause of that development, for many other populations have lived on slaves and remained altogether inconspicuous.

The long-standing controversy as to the relative importance of nature and nurture, to use Galton's "convenient jingle of words," is drawing to an end, and of the overwhelmingly greater significance of nature there is no longer any possibility of doubt. It may be well briefly to recapitulate the arguments on which naturalists rely in coming to this decision both as regards races and individuals. First as regards human individuals, there is the common experience that children of the same parents reared under conditions sensibly identical may develop quite differently, exhibiting in character and aptitudes a segregation just as great as in their colours or hair-forms. Conversely all the more marked aptitudes have at various times appeared and not rarely reached perfection in circumstances the least favourable for their development. Next, appeal can be made to the universal experience of the breeder, whether of animals or plants, that strain is absolutely essential, that though bad conditions may easily enough spoil a good strain, yet that under the best conditions a bad strain will never give a fine result. It is faith, not evidence, which encourages educationists and economists to hope so greatly in the ameliorating effects of the conditions of life. Let us consider what they can do and what they cannot. By reference to some sentences in a charming though pathetic book, "What Is, and What Might Be," by Mr. Edmond Holmes, which will be well known in the Educational Section, I may make the point of view of us naturalists clear. I take Mr. Holmes's pronouncement partly because he is an enthusiastic believer in the efficacy of nurture as opposed to nature, and also because he illustrates his views by frequent appeals to biological analogies which help us to a common ground. Wheat badly cultivated will give a bad yield, though, as $\mathrm{Mr}$. Holmes truly says, wheat of the same strain in similar soil well cultivated may give a good harvest. But, having witnessed the success of a great natural teacher in helping unpromising peasant children to develop their natural powers, he gives us another botanical parallel. Assuming that the wild bullace is the origin of domesticated plums, the tells us that by cultivation the bullace can no doubt be improved so far as to become a better bullace, but by no means can the bullace be made to bear plums.

All this is sound biology; but translating these facts into the human analogy, he declares that the work of the successful teacher shows that with man the facts are otherwise, and that the average rustic child, whose normal ideal is "bullacehood," can become the rare exception, developing to a stage corresponding with that of the plum. But the naturalist knows exactly No. 2339, vor. 93] where the parallel is at fault. For the wheat and the bullace are both breeding approximately true, whereas the human crop, like jute and various cottons, is in a state of polymorphic mixture. The population of many English villages may be compared with the crop which would result from sowing a bushel of kernels gathered mostly from the hedges, with an occasional few from an orchard. If anyone asks how it happens that there are any plum-kernels in the sample at all, he may find the answer perhaps in spontaneous 'variation, but more probably in the appearance of a long-hidden recessive. For the want of that genetic variation, consisting probably, as I have argued, in loss of inhibiting factors, by which the plum arose from the wild form, neither food, nor education, nor hygiene can in any way atone. Many wild plants are half-starved through competition, and transferred to garden soil they grow much bigger; so good conditions might certainly enable the bullace population to develop beyond the stunted physical and mental stature they commonly attain, but plums they can never be. Modern statesmanship aims rightly at helping those who have got sown as wildings to come into their proper class; but let not anyone suppose such a policy democratic in its ultimate effects, for no course of action can be more effective in strengthening the upper classes whilst weakening the lower.

In all practical schemes for social reform the congenital diversity, the essential polymorphism of all civilised communities must be recognised as a fundamental fact, and reformers should rather direct their efforts to facilitating and rectifying class-distinctions than to any futile attempt to abolish them. The teaching of biology is perfectly clear. We are what we are by virtue of our differentiation. The value of civilisation has in all ages been doubted. Since, however, the first variations were not strangled in their birth, we are launched on that course of variability of which civilisation is the consequence. We cannot go back to homogeneity again, and differentiated we are likely to continue. For a period measures designed to create a spurious homogeneity may be applied. Such attempts will, I anticipate, be made when the present unstable social state reaches a climax of instability, which may not be long hence. Their effects can be but evanescent. The instability is due not to inequality, which is inherent and congenital, but rather to the fact that in periods of rapid change like the present, convection-currents are set up such that the elements of the strata get intermixed and the apparent stratification corresponds only roughly with the genetic. In a few generations under uniform conditions these elements settle in their true levels once more.

In such equilibrium is content most surely to be expected. To the naturalist the broad lines of solution of the problems of social discontent are evident. They lie neither in vain dreams of a mystical and disintegrating equality, nor in the promotion of that malignant individualism which in older civilisations has threatened mortification of the humbler organs, but rather in a physiological co-ordination of the constituent parts of the social organism. The rewards of commerce are grossly out of proportion to those attainable by intellect or industry. Even regarded as compensation for a dull life, they far exceed the value of the services rendered to the community. Such disparity is an incident of the abnormally rapid growth of population and is quite indefensible as a permanent social condition. Nevertheless, capital, distinguished as a provision for offspring, is a eugenic institution; and unless human instinct underyoes some profound and improbable variation, abolition of 
capital means the abolition of effort; but as in the body the power of independent growth of the parts is limited and subordinated to the whole, similarly in the community we may limit the powers of capital, preserving so much inequality of privilege as corresponds with physiological fact.

At every turn the student of political science is confronted with problems that demand biological knowledge for their solution. Most obviously is this true in regard to education, the criminal law, and all those numerous branches of policy and administration which are directly concerned with the physiological capacities of mankind. Assumptions as to what can be done and what cannot be done to modify individuals and races have continually to be made, and the basis of fact on which such decisions are founded can be drawn only from biological study.

A knowledge of the facts of nature is not yet deemed an essential part of the mental equipment of politicians; but as the priest, who began in other ages as medicine-man; has been obliged to abandon the medical parts of his practice, so will the future behold the schoolmaster, the magistrate, the lawyer, and ultimately the statesman, compelled to share with the naturalist those functions which are concerned with the physiology of race.

\section{SECTION B.}

CHEMISTRY.

Opening Address by Prof. William J. Pope, M.A., LL.D., F.R.S., President of the Section.

(Concluded from p. 649.)

THE two assemblages can now be described in a quantitative manner by stating the symmetry and also the relative dimensions of each. The cubic assemblage exhibits symmetry identical with that of the cube or the regular octahedron, a symmetry characteristic of so-called holohedral cubic crystals; the relative dimensions in different directions are defined by the symmetry. The assemblage can, in fact, be referred to three axes parallel to the edges of a cube, and as these directions are obviously similar in a cube, their ratios are of the form, $a: b: c=\mathrm{I}: \mathrm{I}: \mathrm{I}$. This expression indicates that if the assemblage, supposed indefinitely extended through space, is moved by a unit distance in either of the three rectangular directions, $a, b$, and $c$, the effect, as examined from any point, is as if the assemblage had not been moved at all.

The symmetry of the hexagonal assemblage is identical with that of a hexagonal prism or of a double hexagonal pyramid, and is that characteristic of the so-called holohedral, hexagonal, crystalline system; the relative dimensions are no longer defined entirely by the symmetry, and are conveniently stated as the ratio of the diameter, $a$, of the prism or pyramid, to the height, $c$, of the pyramid. The ratio, $a: c$, for the assemblage of spheres under discussion can be calculated; it assumes two forms, corresponding to two modes of selecting alternative principal diameters of the prism as unit. The alternative ratios are : $a: c=\mathrm{I}: \mathrm{r} \cdot 6330$ or $a: c=\mathrm{I}: \mathrm{I} \cdot 4 \mathrm{I} 42$.

This somewhat lengthy theoretical discussion has now reached a stage at which it can be applied to the observed facts; the accompanying table (Table I.) states the mode in which crystalline substances of different degrees of molecular complexity distribute themselves amongst the various crystal systems. Of the elements which have been crystallographically examined, 50 per cent. are cubic, whilst a further 35 per cent. are hexagonal; and consideration of the data for these latter shows that they exhibit approxiNo. 2339, VOL. 93] mately the axial ratios characteristic of the hexagonal closest-packed assemblage; thus magnesium shows $a: c=\mathrm{I}: \mathrm{r} \cdot 6242$, and arsenic the ratio $a: c=\mathrm{I} \cdot 4025$.

TABLE I.

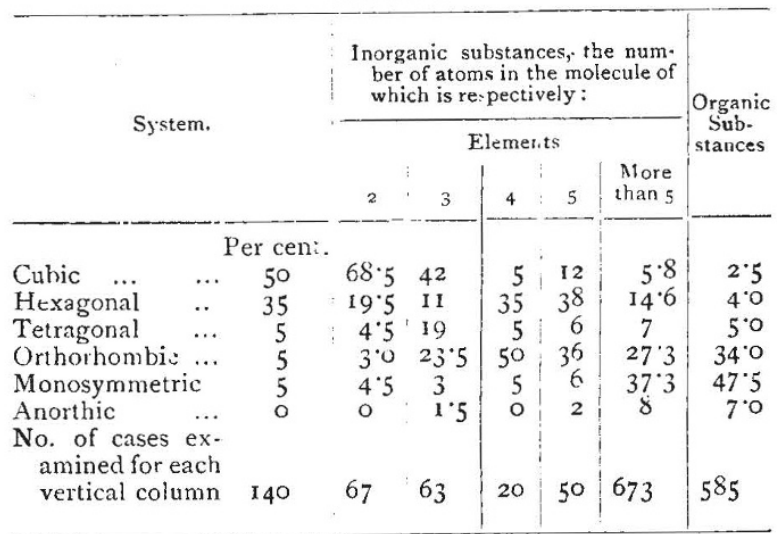

Whilst the crystal structure of some 85 per cent. of the crystalline elements seems to be in general agreement with the simple assumption of equilibrium which has been made, the divergence presented by about ${ }_{5} 5$ per cent. of the elements still awaits explanation. The previous discussion applies to the theoretically simple case of a monatomic element; many of the elements are, however, certainly polyatomic. Imagine, therefore, that in the crystal structure, agreeing with the cubic or hexagonal arrangement just described, the similar atoms are grouped to form complex molecules, each containing two or more atoms; the geometrical effect of this grouping, if any, should be, first, to degrade the symmetry of the structure, and, secondly, to slightly alter its relative dimensions. It would therefore be expected that if the elements which are neither cubic nor hexagonal owe their departure from those systems to molecular aggregation, the crystal dimensions should approximate closely to those of the two ideal assemblages; this is, indeed, found to be the case. Monosymmetric sulphur, for instance, exhibits the axial ratios, $a: b: c=0.995^{8}:$ I $: 0.9988$, $\beta=95^{\circ} 46^{\prime}$; the relative dimensions in the three directions $a, b$, and $c$, are almost the same as in the cubic system, and the angle between the directions $a$ and $c$ is $\beta=95^{\circ} 46^{\prime}$, instead of $90^{\circ}$. This substance has nearly the dimensions of a cubic crystal, and is obviously "pseudo-cubic"; the same is true of all other elements which depart from true cubic or hexagonal symmetry.

The crystalline forms presented by the elements are consequently in accordance with the assumption that the crystal structures are equilibrium arrangements of the component atoms of the two kinds described. It is also indicated that aggregation of the atoms to form molecular complexes is responsible for the departure from simple cubic or hexagonal symmetry; in this connection it is interesting to note that the strongly coloured elements depart most widely from these two systems. Thus, the colourless modifications of carbon and phosphorus are cubic, whilst the black graphite is monosymmetric and the red phosphorus is orthorhombic in crystal form; this is in accordance with the general view that colour is the result of some particular kind of molecular aggregation.

Although so much general correspondence of a quantitative character is to be observed between the observed facts and the anticipations developed from the equilibrium assumption, it has become evident during the last year or two that the conception formed 
as to the nature of the equilibrium which determines the arrangement of the atoms in a crystalline element is of too simple a character. In 1912 Laue showed that on passing a narrow pencil of X-rays through a crystal plate the emergent rays were capable of forming a regular, geometrical pattern of spots upon a photographic plate placed to receive the emergent beam; the pattern of spots thus produced was in agreement with the symmetry of the direction in the crystal plate in which the beam was passed. This discovery was developed and very considerably extended by Bragg, who was able to show that an X-ray beam undergoes reflection at the surface of a crystal plate. The interpretation of the novel results indicates that the homogeneous crystal structure acts upon the X-ray beam much as a solid diffraction grating might be expected to do, and that each deflected transmitted ray is a reflection from one set of parallel planes of atoms in the crystal.

The experimental and theoretical study of the X-ray effects has been prosecuted with brilliant success by W. H. and W. L. Bragg, the result being that a method is now available which makes it possible to determine, with very great probability, the actual arrangement of the constituent atoms in crystal structure. Sufficient time has not yet elapsed for the thorough exploitation of this new and fruitful field of research, but many data are available already for comparison with the conclusions drawn from the consideration of the equilibria possible in crystal structures; it is found that the two methods do not at once lead to identical conclusions. Thus, in accordance with the first method, the structure of the diamond would be indicated at some slight modification of the cubic closest-packed assemblage of equal spheres, the modification consisting in the main of a grouping of sets of atoms which leads to the partial cubic symmetry which the diamond apparently exhibits; one particular mode of grouping which leads to the required result consists in supposing the carbon atoms formed into sets of four, tetrahedrally arranged, two oppositely orientated sets of such tetrahedral groups being distinguished. If each of these tetrahedral groups be replaced by a single point situated at the group-centre, the structure which the Bragg experiments indicate for the diamond is obtained.

The simple geometrical relationship which thus exists between the two suggested structures for diamond raises a suspicion that the particular form in which the assumption of equilibrium is stated requires qualification : that possibly the domain of the carbon atom when packed with others, as in the diamond, does not become converted into a rhombic dodecahedron, but into a polyhedron roughly tetrahedral in shape.

Leaving this particular point for the moment and turning again to Table I., it is seen that the binary compounds, like the elements, also tend to crystallise in the cubic or hexagonal systems; the axial ratios of the hexaeonal binary compounds approximate very closely to the value, $\dot{a}: c=\mathrm{I}: \mathrm{x} \cdot 6230$, calculated for the closest-packed, hexagonal assemblage of equal spheres. The values of cla for all the known cases are: $\mathrm{BeO}-\mathrm{r} \cdot 636_{5}, \mathrm{ZnO}-\mathrm{r} \cdot 6077, \mathrm{ZnS}-\mathrm{r} \cdot 635^{\circ}, \mathrm{CdS}-\mathrm{r} \cdot 62 \mathrm{r} 8$, and $\mathrm{AgI}-\mathrm{I} \cdot 6392$.

Assemblages representing the crystal structures of the cubic and hexagonal binary compounds may be derived from the two closest-packed assemblages of similar spheres already described, by homogeneously replacing one half of the spheres by different ones of the same size. The degrees of symmetry presented by these arrangements are not so high as those of the unsubstituted assemblages; this is in accordance with the fact that the crystals themselves have not the full symmetry of the holohedral cubic or hexagonal system. Thus, on warming a hexagonal crystal of silver iodide, one end of the principal axis $c$ becomes positively, and the other negatively, electrified. The axis $c$ is thus a polar axis, having different properties at its two ends; this axis will be found to be polar in the model. Again, when hexagonal silver iodide is heated to $145^{\circ}$, it changes its crystalline form and becomes cubic; this so-called polymorphous change can be imitated in the hexagonal model by slightly shifting each pair of layers of spheres in the assemblage.

A very close agreement thus exists between the properties of the assemblages deduced and the observed properties of those binary compounds which crystallise in the cubic or hexagonal systems. The remaining 12 per cent. or so are not, in general, pseudo-cubic or pseudo-hexagonal, and it is noteworthy that they comprise those binary compounds in which the two component elements have not the same lowest valency; amongst them are the substances of the compositions, $\mathrm{PbO}, \mathrm{FeAs}, \mathrm{HgO}, \mathrm{AsS}$, and $\mathrm{CuO}$.

On comparing the structures of the binary crystalline compounds indicated by the foregoing method of consideration with those deduced by the Braggs, discrepancies are again obvious; again, however, the former assemblage is converted into the latter by replacing groups of spheres by their group-centres. The relation thus rendered apparent is once more a suggestion that the type of equilibrium conditions originally assumed is too simple. It will be seen, however, that the Bragg results furnish a proof of one part of the assumption made concerning equilibrium, namely, that each component atom operates separately; the discussion of the properties of crystals on the assumption that the crystal structure may be regarded as built up of similar mass-points, due to the mathematical physicists of the last century, therefore $1 \mathrm{e}-$ quires to be reopened. Thus, the Bragg structure of rock-salt is represented by dividing space into equal cubes by three sets of parallel planes and replacing the cube corners encountered along the directions of the cube edges by chlorine and sodium atoms alternately; each chlorine atom then has six sodium atoms as its nearest and equally distant neighbours. IVith which of the latter the one chlorine atom is associated to form a molecule of sodium chloride is not apparent from the nature of the crystal structure.

Time need not be now occupied with the further discussion of the crystalline structure of simple substances; until the discovery of the X-ray effects thus briefly described, no direct method of determining those structures was available, and, in view of the paucity of the experimental data, only the possibilities of arrangement could be considered in the light of the Barlow-Pope mode of treatment. It will, however, be useful to review some of the results which accrue from this latter method of regarding the problem of crystal structure in general.

Taking the general standpoint, which is also in accordance with the Bragg results, that cach component atom of a crystalline structure has a separate spacial existence, and premising that the atomic domains are close-packed in the assemblage in accordance with some particular type of equilibrium law, it becomes obvious that crystalline structure presents a volume problem. The law arrived at after a careful investigation of the subject-the so-called law of valency volumes-states that in a crystalline structure, the component atoms occupy domains approximately proportional in volume to the numbers representing the fundamental valencies of the elements concerned; the student of the subject of molecular volumes will hardly accept this conclusion without convincing evi- 
dence of its correctness-it indicates, for instance, that in crystalline potassium sulphate, if the atomic volume of potassium is taken as unity, those of sulphur and oxygen each have the value two. Many different lines of crystallographic argument converge, however, to this law, and, if the latter is in the end found to be incorrect, it at least represents something fundamentai which still awaits enunciation in a more generally acceptable form. A few illustrative instances may be quoted.

If valency be a volume property, the relation should be revealed in the compositions of chemical substances, especially those of composite character. The sum of the valencies in potassium sulphate, $\mathrm{K}_{2} \mathrm{SO}_{4}$, is 12 , and in ammonium sulphate, $\left(\mathrm{NH}_{4}\right)_{2} \mathrm{SO}_{4}, 24$, just twice the number; the two substances are so closely related that they crystallise together to form "solid solutions" (isomorphous mixtures. Similarly, in the alums, such as $\mathrm{K}_{2} \mathrm{SO}_{4}+\mathrm{Al}_{2}\left(\mathrm{SO}_{4}\right)_{3}+24 \mathrm{H}_{2} \mathrm{O}$, the valencies are $12+36+96$; the sum of the valencies of the water present, 96 , is just twice that, 48 , of those exhibited by the metallic sulphates. Similar curious numerical relationships occur in each of the well-defined series of double salts.

Again, if the valency volume law hold for two substances of different crystalline form, such as orthorhombic rubidium nitrate, $\mathrm{RbNO}_{3}$, and rhombohedral sodium nitrate, $\mathrm{NaNO}_{3}$, the metal, the nitrogen and the oxygen in each compound should have the respective atomic volumes, 1,3 , and 2 . As the substances differ in density the absolute values of the atomic volumes of nitrogen and oxygen will differ in the two substances as examined in the same temperature; the ratios of the atomic volumes in either compound should, however, be as stated. Considering this conclusion in conjunction with the fact that these crystalline compounds represent svmmetrically constructed assemblages, it would seem that the relative dimensions of the one crystal structure should be traceable in those of the other. Orthorhombic rubidium nitrate exhibits the axial ratios, $a: b: c=$ $1.7336: 1: 0.7106$, three rectangular coordinates, $a, b$, and $c$, being used as the directions of reference; rhombohedral sodium nitrate exhibits $a: c=1: 0.82 ; 6$, the coordinates being three axes, $a$, making angles of $120^{\circ}$ in one plane, and a fourth axis $c$, perpendicular to $a$. On converting the axial system of sodium nitrate into a simple set of rectangular axes similar to those used for rubidium nitrate, the value, $a: c=$ I : $0.82 \% 6$, becomes

$$
a: b: c=\mathrm{I} \cdot 7320: \mathrm{I}: 0.7 \mathrm{I} 5 \mathrm{I} .
$$

These values approximate very closely to those obtained by direct measurement of the orthorhombic rubidium salt. It seems difficult to avoid the conclusion that the two dissimilar crystalline structures are built up by the arrangement of layers or blocks of the same relative dimens:ons in two different ways, the molecule of sodium nitrate, $\mathrm{NaNO}_{3}$, possessing practically the same relative dimensions as that of rubidium nitrate, $\mathrm{RbNO}_{3}$; this, of course, is in disaccord with the classic conception of atomic volume, but agrees entirely with the valencv volume law.

Another remarkable body of evidence is found in the interpretation of many morphotropic relationships between organic and inorganic substances which have been long recognised but have hitherto eluded interpretation. The description of one or two cases will make the bearing of the law of valency volumes clear in this connection.

$d$-Camphoric anhydride, $\mathrm{C}_{10} \mathrm{H}_{14} \mathrm{O}_{3}$, and $d$-camphoric acid crystallised with acetone, $\mathrm{C}_{10} \mathrm{H}_{16} \mathrm{O}_{4}, \mathrm{r} / 2\left(\mathrm{CH}_{3}\right)_{2} \mathrm{CO}$, both crystallise in the orthorhombric system and exhibit the axial ratios stated in the following Table II. :-

TABLE II.

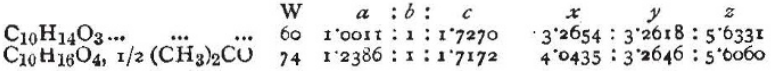

The ratio $c / b$ is approximately the same in the two cases and general similarity exists between the two crystalline substances. It will be observed that the values of $a / b$ are very nearly in the ratio of the sums of the valencies, $W$, making up the two molecular complexes, namely, $60: 74=100: 123$. This and similar cases may be more conveniently discussed with the aid of the so-called equivalence parameters; these are the edge lengths, $x, y$, and $z$, of a parallelepipedon of which the volume is $W$, the sum of the valencies in the molecule, and of which the linear and angular dimensions express the crystallographic axial ratios. Thus, for orthorhombic substance $x y z=\mathrm{W}$, and $x: y: z=a: b: c ;$ the equivalence parameters of the two substances under discussion are givan in the table, and it will be seen that whilst $y$ and $z$ are almost identical for the two, the $z$ values differ considerably. This correspondence indicates clearly that in passing from camphoric anhydride to the acetone compound of the acid the mass added to the molecular complex, $\mathrm{H}_{2} \mathrm{O}+\mathrm{I} / 2\left(\mathrm{CH}_{3}\right)_{2} \mathrm{CO}$, occupies a volume proportional to the number of valency units which its contributes to the structure.

A very remarkable relation has been long recognised between the crystalline forms of the three minerals chondrodite, $\mathrm{Mg}_{3}\left(\mathrm{SiO}_{4}\right)_{2}, \quad 2 \mathrm{Mg}(\mathrm{F}, \mathrm{OH})$, humite, $\mathrm{Mg}_{5}\left(\mathrm{SiO}_{4}\right)_{3}, 2 \mathrm{Mg}(\mathrm{F}, \mathrm{OH})$, and clinohumite, $\mathrm{Mg}_{7}\left(\mathrm{SiO}_{4}\right)_{4}, \quad 2 \mathrm{Mg}(\mathrm{F}, \mathrm{OH})$; the crystalline forms are referable to three rectangular directions, $a, b$, and $c$, and the ratio $a: b$ is practically the same for all three minerals. The relationship is at once elucidated by the law of valency volumes in a simple manner. In the molecules of the three substances the sums of the valencies of the constituent atoms are respectively 34,48 , and 62 ; it follows from the law that these numbers are proportional to the relative volumes of the several molecules. The ratios, $a: b: c$, being known, the dimensions can be calculated of solid rectangu'ar blocks having these volumes and having edge lengths proportional to the axial ratios, $a: b: c$. The equivalence parameters, $x, y$, and $z$, thus calculated are given in the following Table III.; the first observation of importance to be made is that the equivalence parameters, $x$ and $y$, remain practically constant throughout the series of three minerals.

It will be seen that chondrodite and humite, and humite and clinohumite, differ in molecular composition by the quantity, $\mathrm{Mg}_{2}\left(\mathrm{SiO}_{4}\right)$; they form a series in which the increment of composition is $\mathrm{Mg}_{2}\left(\mathrm{SiO}_{4}\right)$. Subtracting this increment from the composition of chondrodite, the residue, $\mathrm{Mg}_{2}\left(\mathrm{SiO}_{4}\right), 2 \mathrm{Mg}(\mathrm{F}, \mathrm{OH})$, is left. This is the composition of the mineral prolectite, and the increment. $\mathrm{Mg}_{2}\left(\mathrm{SiO}_{4}\right)$, is the composition of the mineral forsterite.

If the law of valency volumes be correct the equivalence parameters of forsterite should be the $x$ and $y$ of the first three minerals, and a value $z$ which is the difference between the $z$ values of chondrodite and humite, or of humite and clinohumite; further, prolectite should have $x$ and $y$ values identical with those of the other four minerals and a $z$ value which is the difference of the $z$ values of chondrodite and forsterite. It is thus possible to calculate the equivalence parameters of forsterite and prolectite without using data determined on these two minerals, and to compare the values so obtained with those calculated from

NO. 2339, VOL. 93] 
the observed axial ratios of forsterite and prolectite. All the values referred to are given in Table III., and it will be obvious that the agreement between the calculated and the observed equivalence parameters is very close; as this agreement could not occur without the operation of the law of valency volumes, which was deduced from entirely different data, strong confirmation of the accuracy of the law is provided.

TABLe III.

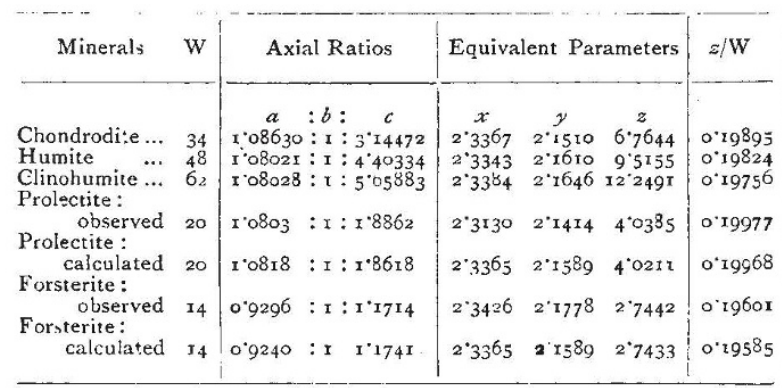

The several illustrations of the operation of the law of valency volumes have been quoted in detail for the purpose of showing how difficult it is to avoid the conclusion that this deduction represents some physical reality. It may be traced in connection with quantitative data of other kinds; during the last few years it has been very successfully applied by Le Bas to the interpretation of the molecular volumes of liquid substances.

From what has been already said it will be seen that the great problem as to the relation between crystal structure and chemical constitution, of which the solution seems imminent, is a stereochemical one; assemblages must be built up in accordance with the principle of homogeneity and in some form of closepacking, in which each component atom of a chemical molecule is represented as the sole occupant of some specific solid area. The properties of these assemblages must also be in agreement with the crystallographic measurements and the $\mathrm{X}$-ray photographs yielded by the substances represented.

A brief indication may be given of what has been already effected in this connection. The normal paraffin hydrocarbons of the general composition $\mathrm{C}_{n} \mathrm{H}_{2 n+2}$ consist of a chain of the composition $\left(\mathrm{CH}_{2}\right)_{n}$, to each end of which one hydrogen atom is attached; in accordance with the principles already indicated, a close-packed assemblage of the empirical composition $\mathrm{CH}_{2}$ can be constructed from carbon and hydrogen spheres of the respective volumes 4 and I, of such a nature that it can be divided by planes into blocks, each made up of strings of the composition $\left(\mathrm{CH}_{2}\right)_{n}$, or $. \mathrm{CH}_{2} \cdot \mathrm{CH}_{2} \ldots . \mathrm{CH}_{2} \cdot \mathrm{CH}_{2}$. At each plane of cleavage of the assemblage hydrogen spheres can be inserted in appropriate numbers so that closepacking is restored when the cleavage faces are brought together again; the assemblage will then have the composition $\mathrm{H} .\left(\mathrm{CH}_{2}\right)_{n} . \mathrm{H}$, and may be geometrically partitioned into units each representing one molecular complex of a normal paraffin. It is noteworthy that these units exhibit the configurations indicated by the van 't Hoff-Le Bel conception for the normal paraffins. Other assemblages can be constructed which represent in a similar manner the secondary and tertiary paraffins, and all these assemblages are of one particular geometrical type, that which corresponds to the chemical behaviour characteristic of the paraffins. In these assemblages replace- ments may be effected so as to introduce new geometrical features of arrangement corresponding to the presence in the molecule of an ethylenic or an acetylenic bond, and thus other classes of hydrocarbons can be represented in accordance with the conception of close-packing; the process can be extended to the polymethylene and aromatic hydrocarbons and to their substitution derivatives, and throughout a close correspondence is observed between the numbers of isomerides possible, with their constitutions and configurations, and the experimental facts.

Many considerations indicate the fruitfulness of the mode of regarding organic substances just briefly sketched; one may be more particularly specified. An assemblage representative of benzene has been suggested which accords with the crystalline form and chemical properties of the hydrocarbon, and can be geometrically partitioned into units, each representing a single molecule. The equivalence parameters of the substance are

$$
x: y: z=3 \cdot 1.01: 3.480: 2 \cdot 780 .
$$

The dimension $y$ is twice the diamater of a carbon sphere, and that of $z$ slightly less than the sum of the diameters of a carbon and a hydrogen sphere. Now a dimension approximating closely to the $z$ value for benzene can be found amongst the equivalence parameters of large numbers of aromatic compounds, indicating that in these crystalline substances the benzene complexes are stacked one upon the other so as to preserve the $z$ dimension, but that the columns so formed are pushed apart in the derivatives to an extent sufficient to admit of the entrance, in closepacking, of the substituting radicles. A few cases of this kind were quoted by Barlow and myself, and many others were discovered by Jerusalem; ${ }^{6}$ quite recently the subject has been subjected to a very thorough quantitative examination by Armstrong, Colgate, and Rodd. ${ }^{7}$ The exhaustive nature of the experimental work of these latter authors and the care with which their conclusions are drawn leave little room for doubt as to the accuracy of their main contention, namely, that the crystallographic method affords material from which the stereochemical confisurations of aromatic substances can be deduced.

If cystallography is to be used as a tool in the service of stereochemistry in anything like the way which has been briefly sketched in this address, a number of important results should accrue. We have seen that in the structure assigned to rock-salt, each sodium atom is identically related to six chlorine atoms; only when the crystal is disintegrated by solution in water does the necessity arise for a choice to be made, the sodium atom then selecting one particular chlorine atom as a mate. Even then the sodium chloride molecule present in solution appears to spend the greater part of its time in dissociation, namely, in the act of changing its partner. There is thus in the theory of crystal structure something which bears a superficial relationship to electrolytic dissociation, and the further study of this aspect of the subject may be fruitful.

Again, the solid crystalline structures which we have attempted to build up present, as one essential feature, the property that they can be partitioned geometrically into unit cells, each composed of one molecule of the substance; thus, the rock-salt structure can be partitioned into cells each representing the molecule $\mathrm{NaCl}$. In this instance, the partitioning can be performed

6 Trans. Chem. Soc., 1909, 95, 1275

7 Trans. Chem. Soc., rgro, 97, $1577^{8}$; Proc. Roy. Soc., A, 1912, 87, 204 ; 19 $13,89,292$; 1914, 90, гіл. 
in a variety of ways corresponding to the allocation of one particular sodium atom to either of six chlorine atoms; the alternative modes of partitioning lead to the production of molecular units of identical configuration. In many cases, however, alternative methods of geometrically partitioning the assemblage representing the crystalline structure do not yield units of the same configuration; thus, the assemblage representing phloroglucinol can be geometrically partitioned in two distinct ways. Each of these gives a unit of the composition $\mathrm{C}_{6} \mathrm{H}_{6} \mathrm{O}_{3}$, but the configuration of the unit of the one partitioning corresponds to the chemical structure of the $1: 3: 5$-trihydroxybenzene,<smiles>O=C(O)C=CC(=O)O</smiles>

whilst the other exhibits the structure of the symmetrical triketohexamethylene,

$$
\mathrm{H}_{2} \mathrm{C}\left\langle\begin{array}{l}
\mathrm{CO} . \mathrm{CH}_{2} \\
\mathrm{CO} . \mathrm{CH}_{2}
\end{array}>\mathrm{CO} .\right.
$$

A new suggestion is thus made to the effect that tautomerism consists in the possibility of geometrically partitioning the close-packed assemblage in two or more alternative ways, each giving molecular units of the same composition but of different constitutions. The idea that in the occurrence of tautomerism some component atom wanders from one position to another in the molecule is thus rejected; the change in constitution arises from the transference of atoms as between two or more molecules. As the older conceptions of the mechanism of tautomerism do not provide a satisfactory explanation of the experimental facts, the suggestion now made is perhaps worthy of consideration.

The new line of work has many bearings upon the subject of chemical change; thus, the assemblage which is assigned to acetylene (or methylacetylene) is convertible, by symmetrical distortion, into that representing benzene (or the $1: 3: 5$-trimethylbenzene, mesitylene. Further, the great change in chemical behaviour which accompanies many types of chemical substitution is possibly connected with the manner in which the actual atomic volumes are affected by the replacement; on converting benzene, in which the atomic volumes of carbon and hydrogen are as $4: r$, into bromobenzene, a considerable increase in molecular volume occurs. The atomic volumes of carbon and hydrogen still, presumably, preserve the $4: 1$ ratio, and the volume appropriated by the entering bromine atom is approximately the same as that occupied by each hydrogen atom already present; the actual atomic volumes of carbon and hydrogen must thus be supposed to have increased during the production of bromobenzene. It can hardly be supposed that this fundamental volume change, even apart from a distortion of the aromatic ring arising from slight inequality of hydrogen and bromine atomic domains in the molecule, could occur without the exhibition of considerable differences in chemical properties as between benzene and bromobenzene.

Whatever view may be taken as to the accuracy of the conclusions concerning the relation between crystal structure and chemical constitution which are briefly discussed in the present address, no critic will be disposed to doubt that wide developments in chemical science will result from the cultivation of crystal study: it seems clear that any satisfactory theory of the solid state must be largely crystallographic in character, The chief hindrance to progress at present consists

NO. 2339, VOL. 93] in the lack of chemists trained in modern crystallographic methods; in my own country the only school in which chemical students were trained in crystallography, dissociated from mineralogy, was founded by Dr. Henry E. Armstrong and Sir Henry A. Miers in I886. After doing a vast amount of valuable educational work this school has recently been allowed to become extinct.

In a presidential address to the Mineralogical Society in 1888, Mr. Lazarus Fletcher remarked that "a knowledge of the elements of crystallography, including the mechanics of crystal measurements, ought to be made a sine qua non for a degree in chemistry at every university." Twenty-five years later we find that no European university has applied this principle, and in consequence the chemical crystallographer has the greatest difficulty in making himself intelligible to his purely chemical colleagues. May I, in concluding, express the hope that the colonial universities, less fettered by tradition than their olcer sisters, may lead in the work of placing the subject of crystal structure in its legitimate position as one of the most important branches of modern physical chemistry?

\section{UNIVERSITY AND EDUCATIONAL INTELLIGENCE.}

Glasgow.-The Principal wishes it to be known that the University will do what it can to safeguard the academic interests of undergraduates on military duty. In relation to attendance on courses of instruction, to duration of study, to periods of notice required, etc., account will be taken of a student's absence on military duty to ensure, if possible, that his graduation shall not be unduly delayed.

The authorities of the Royal Agricultural College, Cirencester, wish it to be known that every endeavour will be made to prevent students who are undertaking army or other patriotic work from being thereby penalised as regards their courses of study.

THE Vice-Chancellor of the University of Liverpool states that although the Council and Senate have not met since the declaration of war, it may be assumed (I) that the University courses will begin on the appointed day; (2) that in due time everything will be done that can be done to safeguard the interests of members of the staff and of students who have offered themselves for national service at home or abroad. It is also announced that at Durham University the term will begin as usual in October, and that no member of the Durham Colleges will suffer any academic disability by reason of absence on any form of national service.

THE fifty-fifth annual report of the Cooper Union for the Advancement of Science and Art has been received from New York. The union governs and finances many departments of higher education, and in the report its director gives full particulars of the work done during the year ending June, I9I4, and directs special attention to the development of the technical school. We notice the resignation of Prof. Robert Spice, after twenty-five years' service in Cooper Union as professor of chemistry and head of the department of chemistry. Since rgoo Prof. Spice has devoted the whole of his time to the Cooper Union; beginning with some twenty students the attendance has steadily increased until now the limits of the capacity of his department have been reached. 